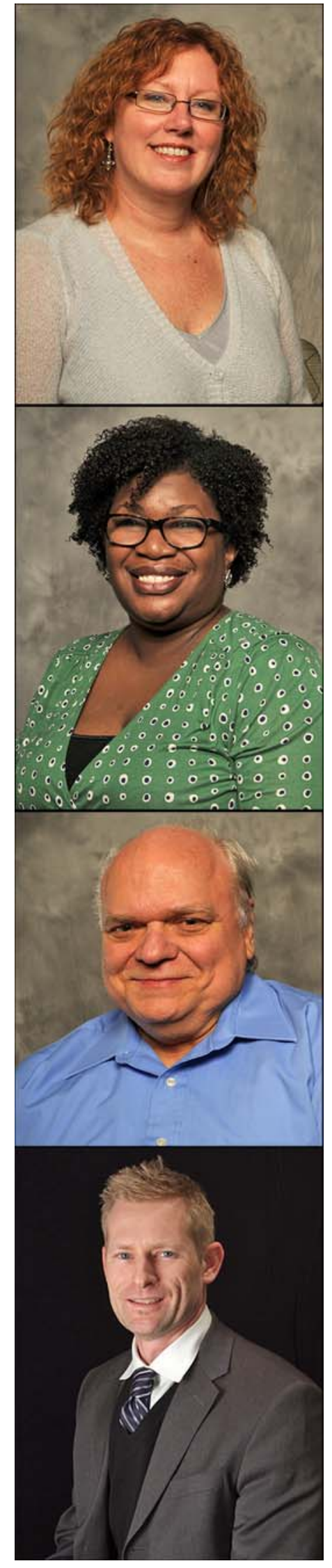

Frances McClellan, RN, MSN; Monique Washington, RN, MS; Robert Ruff, MD, PhD; Stephen M. Selkirk, MD, PhD

\section{Developing a system of care for ALS patients at the Louis Stokes Cleveland VA Medical Center, Spinal Cord Injury Division}

\section{INTRODUCTION}

Amyotrophic lateral sclerosis (ALS), also referred to as Lou Gehrig's disease, is a fatal motor neuron disease characterized by rapidly progressive weakness, dysarthria, dysphagia, and respiratory failure. Fifty percent of patients will die within 3 years of diagnosis and 95 percent within 5 yearsmainly from respiratory failure [1]. The only available treatment, riluzole, has limited efficacy, prolonging survival by 3 months [2-3]. Although familial cases have led to the identification of associated genetic loci, the etiology of sporadic cases is unknown. There is, however, an association between military service and the development of ALS [4]. Hence, in 2008, ALS became a presumptively compensable illness for all Veterans with 90 days or more of continuously active service in the military. This provides the Veteran full access to medical care, medication management, durable medical equipment (DME), and monthly financial compensation.

Since this decision in 2008, there has been a growing appreciation for the level of Department of Veterans Affairs (VA) benefits associated with the diagnosis of ALS, and subsequently more Veterans have entered the VA medical system with a diagnosis of ALS, both at the Cleveland VA Medical Center and in Veterans Integrated Service Network (VISN) 10 in Ohio. Between 2005 and 2010, the spinal cord injury (SCI) outpatient clinic treated 19 patients with ALS, compared with 60 patients in years 2011 to 2012 alone.

This increased awareness of VA benefits at the outset resulted in Veterans presenting at their first evaluation with advanced stages of ALS, characterized by speech, swallowing, and breathing problems. We found many of the Veterans and their family members psychologically unprepared to cope with the disease progression, often times expressing anger or fear during the initial evaluation. Most patients lacked a clearly defined plan for their future care. The rapid progression of this disease resulted in both the Veteran and the staff being unprepared to cope with the need to make imminent medical decisions regarding percutaneous nutrition, noninvasive versus invasive ventilation, and other complex end-of-life decisions. The processes that were in place to provide care for patients with SCI, although interdisciplinary in nature, lacked the speed and complexity required to care for patients with a rapidly progressive neurodegenerative disorder.

The realization that our current paradigm of care needed to be modified to provide excellent medical services to patients with ALS led to the development of a joint workgroup between the SCI and the Neurology Services. 
The overarching goal of this workgroup was to address care needs and improve processes for Veterans with ALS. This team recognized the complexity of ALS care and looked for solutions to address the unique needs of Veterans with ALS, which included rapid medical management of respiratory issues, nutritional needs, psychological support, education, and providing end-of-life care while expanding the interdisciplinary approach already in place on the SCI service.

\section{BACKGROUND}

\section{ALS and Veterans}

ALS occurs in all major countries worldwide, with higher rates in the United States and England [5]. Approximately 5,600 new cases are diagnosed in the United States each year. The estimated prevalence in the United States is 5 per 100,000 people [6]. About 5 percent of cases are attributed to the inheritance of genetic defects, many of which have been identified; most of these follow an autosomal dominant inheritance pattern. The remaining 95 percent of cases are considered sporadic (nonfamilial) and of unknown etiology. Interestingly, cohorts have been identified suggesting possible causative relationships between the disease and various factors, including pesticide exposure [7], head trauma [8], strenuous physical activity [9], and heavy metal exposure [10]. Similarly, a series of published articles beginning in 2000 suggested the possibility that military service was associated with the future development of ALS. The initial study [11] focused on the risk to deployed gulf war Veterans compared with nondeployed gulf-era Veterans. The study demonstrated an increase risk in the deployed group but was limited by short follow-up time and a low number of affected individuals. Haley examined the incidence of ALS in deployed gulf war Veterans compared with incidence in the general population in the United States [12]. Although this publication was more stringent in terms of the diagnosis and only included patients 45 years of age or younger, the study failed to sex-adjust control data for the overwhelmingly male Veteran group, likely leading to an overestimation of the reported increased risk to Veterans. Two related publications further suggested a relationship between service, deployment, and ALS [13-14]. These studies compared the number of cases of ALS in deployed and nondeployed Veterans in the 10-year period following the end of the gulf war. The comparison of risk between deployed and nondeployed Veterans identified a striking twofold increase in age-adjusted risk for the former cohort. However, limitations were again identified [15] restricting the overall interpretation of the study. Finally, Weisskopf et al. published the best quality cohort study on the subject [4]. This study examined the risk to Veterans serving between 1910 and 1982 and demonstrated a 1.5 times increased risk associated with service during this time period. This is important because it demonstrated an increased risk regardless of wartime or nonwartime service moving beyond the studies focusing on gulf war Veterans and suggests that military service in general results in increased risk of future disease development.

These reports prompted VA to ask The National Academies in 2005 to review the potential connection between military service and a diagnosis of ALS. This task was assigned to the Institute of Medicine (IOM). November 10, 2006, Amyotrophic Lateral Sclerosis in Veterans: Review of the Scientific Literature concluded that "there is limited and suggestive evidence of an association between military service and later development of ALS" [16]. The progressive and often rapid disease course coupled with the IOM report justified then-Secretary James Peake's decision to make ALS a presumptively compensable illness. In a press release, he stated, "There simply isn't time to develop the evidence needed to support compensation claims before many Veterans become seriously ill. My decision will make those claims much easier to process, and for them and their families to receive the compensation they have earned through their service to our nation." The compensable status referred to Veterans with 90 days or more of continuously active service in the military. On September 23, 2008, this presumptive status was applied to all new applications following that date or that were pending before VA, the U.S. Court of Appeals for Veterans Claims, or the U.S. Courts of Appeals for the Federal Circuit. 


\section{Proposed System of Care}

The Chief Patient Care Services Officer charged a National Task Group to develop comprehensive services for Veterans with ALS based on national best practices. VA healthcare requires timely provision of patient-centric care delivered with support to caregivers articulated through standardized recommendations. Standardization assures that each Veteran is offered consistent support and treatment options to help manage the disease, including the impairments, complications, and functional problems that result from ALS. The number of Veterans who will receive this care and benefits can be estimated based on multiple factors. Over the last four fiscal years, 3,581 Veterans with a diagnosis of ALS were treated in the VA systems. The number of new cases diagnosed in Veterans can be estimated based on the literature reviewed in the IOM report, which supports an annual incidence of 4.5 cases per 100,000, which would result in an estimated annual incidence of 1,055 Veterans with new onset ALS and a possible Veteran prevalence of 4,220 given current life expectancy exceeding 3 years. However, it is unknown how many patients will move from private sector care into the VA system because of the designation of service connection for ALS.

The proposed plan [17] takes into account that ALS varies considerably among individuals regarding site of onset and rate of progression [18-19], as well as the variability in a person's cultural, spiritual, personal, circumstantial, social, and family situations. Care is provided in a relationship of respect in which the medical provider guides the patient with information about his or her conditions, options, risks, and benefits. In keeping with VA's patient-centered care initiative that shifts focus of care from solely disease management to include a "personalized, proactive, patient drive approach" (www.va.gov/health/NewsFeatures/20120827a.asp), the mission of the ALS System of Care is to address and manage the multiple medical, physical, functional, psychological, and social effects of ALS to ameliorate symptoms and enhance quality of life of Veterans with ALS through clinical care, education, and research.
The proposal recommends that this care be provided through the establishment of ALS interdisciplinary care teams throughout the VA system. A regionalized system of primary care providers at each VA medical facility organized around a VISN ALS interdisciplinary team will comanage coordinated ALS care within each VISN. An ALS interdisciplinary team should be established in at least one VA medical facility for each VISN, with referrals within each VISN supplemented by primary care providers at each VA medical facility and a telehealth network to facilitate nationwide coverage. These regional specialized teams will work in conjunction with local primary care providers or home-based primary care teams, and as appropriate, hospice and palliative care services. The overarching goal will be the efficient delivery of comprehensive care, benefits, and services while limiting the Veteran's need to travel to obtain this care. Through this system, the regional ALS center can direct care from diagnosis by taking advantage of pre-existing essential disciplines at regional centers and end-of-life care utilizing VAspecific programs such as Home-Based Primary Care and integrated hospice and palliative services delivered locally. As a unified healthcare system, the VA allows for a seamless transition of care as the disease progresses while maintaining the overall mission of providing patient-centered, high-quality care using principles of Patient Aligned Care Teams. The care teams will utilize the VA's Computerized Patient Record System, VA national clinical databases, and telehealth resources to improve care coordination quality, access, and efficiency.

Finally, the proposal confirms the VA dedication to providing the highest level of care to Veterans, stating that care must conform to current clinical practice guidelines for ALS care for standardization purposes and meet or exceed community standards of care for patients with ALS.

\section{Developing ALS Interdisciplinary System of Care}

The proposal identifies potential regional ALS centers and challenges them to implement the care plan. Two key factors contribute to this challenge. The first is the complex and progressive nature of ALS. The disease usually commences as weakness 
in one limb with progression to other limbs, followed by involvement of swallowing and breathing. However, less commonly, the disease begins with bulbar involvement (speech, swallowing, and breathing) prior to limb weakness. Beyond this, the rate of symptom progression is highly variable between patients [19]. Most patients will progress rapidly, and if not anticipated, the timely delivery of health services will not be accomplished. These health services can be extensive because disease progression is associated with high levels of disability (functional tetraplegia, inability to communicate), and depending on a patient's decisions regarding intervention (e.g., percutaneous endoscopic gastrostomy [PEG], artificial ventilation), these services may need to be provided for only months or in some cases far longer.

The second factor involves the complexity of integrating multiple different services into a cohesive, high-functioning interdisciplinary team within the pre-existing medical center. The importance of the interdisciplinary system of care has been well documented for patients with ALS. Evidencebased research has shown that comprehensive management improves outcomes in patients with ALS [20-21]. Comprehensive care encompasses a physician, physical therapist, occupational therapist, speech pathologist, dietician, social worker, respiratory therapist, and nurse case manager. Patient care and survival were examined and there was increased utilization of riluzole, PEG tube placement, and noninvasive ventilation; fewer hospital admissions; and better coordination of care when it took place in a comprehensive ALS clinic. ALS specialized clinics that incorporated multidisciplinary care independently predicted longer patient survival and a higher quality of life [22].

Within VA, the SCI system of care most closely aligns with the Veterans Health Administration National Directive in providing ALS care. The SCI centers have interdisciplinary teams in place that provide coordinated services to highly complex patients that require specialized adaptive equipment and DME. These teams address and manage multiple medical, physical, functional, psychological, and social effects associated with extreme disability to ameliorate symptoms and enhance quality of life of
Veterans with SCI through quality interdisciplinary clinical services, education, and research. In addition to the permanent members of the SCI team, the SCI system of care is accustomed to working with nutrition, speech pathology, sleep/pulmonary/respiratory services, gastroenterology (GI) and anesthesiology, prosthetics, hospice, and chaplain services.

At the Louis Stokes Cleveland VA Medical Center, we have combined the SCI team with the additional team members mentioned previously to create and integrate an ALS interdisciplinary team into the pre-existing SCI division. This team has worked together to create processes and protocols that work more efficiently and effectively than the traditional medical model in caring for individuals with ALS. Here, we present examples of how current protocols and systems of care were modified to specifically address the needs of patients with ALS.

\section{Respiratory Failure}

Veterans with ALS inevitably develop respiratory failure. In our experience, most patients with ALS elect to receive bilevel positive airway pressure (BiPAP) to improve oxygenation and quality of life and to prolong life [23]. However, the system for delivering BiPAP to patients on the SCI division often took months, not only to schedule an overnight sleep study, but then to have the equipment delivered to patients. Furthermore, compliance with BiPAP was suspect because of lack of effective follow-up and aggressive modification to make patients more comfortable. The overall process from identification of a patient needing BiPAP to delivery of a machine was approximately 6 months. As alluded to previously, the rapid disease progression makes this time course incompatible with the effective delivery of medical care to patients with ALS proposed by the national directive. To address this issue, we created an ALS Comfort BiPAP procedure that allows for an abbreviated sleep study lasting 3 to $5 \mathrm{~h}$ and results in the distribution of an appropriate BiPAP machine on the same day. This procedure allows us to make an appointment for a symptomatic patient to coincide with other appointments and issue a device on the same day. Furthermore, home respiratory services follow-up with the patient shortly after the device is 
supplied to address problems such as mask discomfort or anxiety when using the device. We believe this significantly enhances compliance. Finally, we have initiated BiPAP in patients earlier than current clinical practice parameters suggest is necessary [24]. Although the initial impetus to do this was the long wait to receive the device, we continue to offer a device as early as possible despite our streamlined process described previously. The rationale for this is twofold. First, early delivery of the device provides time for the patient to become comfortable using the BiPAP, again, acting to enhance compliance when the machine is actually required to support breathing. Second, evidence suggests early BiPAP may improve lung compliance and prolong survival in patients with ALS [25].

Finally, because the disease is fatal and many patients use equipment for a very brief time, the team developed a rental system through our prosthetic service that reduces the cost of purchasing expensive BiPAP machines, pulmonary vests, and cough assistive devices. In addition, for those purchased, parts of these can be cleaned, sterilized, and reused, offsetting some of the recurring costs of using these pieces of equipment.

\section{Progressive Dysphagia}

As described for respiratory failure, the progression of ALS ultimately results in an inability to swallow and speak. Clinical practice guidelines recommend that when patients develop dysphagia they consider PEG tube placement based on the risks and benefits of the procedure [24]. The determinant of risk is primarily the patient's forced vital capacity, which is also compromised with disease progression [26]. However, the clinical picture is further complicated by the fact that most Veterans with ALS do not want artificial ventilation but do desire PEG tube placement. Respiratory failure associated with sedation during the PEG tube placement may result in ventilator dependence that cannot be reversed because of neuromuscular weakness. This is a life-altering complication from a seemingly simple procedure that is relatively unique to patients with ALS. To address this potentially serious complication and better define risk for patients, we have worked with the GI and anesthe- siology teams to develop a process to ensure safe monitoring and administration of sedation. Patients undergo pulmonary function tests, arterial blood gas, and ALS-specific anesthesia evaluation prior to the procedure. This is followed by GI evaluation and then an interdisciplinary team meeting regarding risk. If the risk is acceptable, the procedure is carried out in the GI suite with Anesthesia present to assist with sedation and monitoring of respiratory status. Afterward, patients are monitored closely for respiratory compromise. If symptoms develop, the patient is transferred to the medical intensive care unit, where BiPAP is initiated and all attempts are made to prevent the need for intubation and artificial ventilation. After successful PEG placement, the patient returns to the SCI service for PEG use and care training prior to discharge. Using this interdisciplinary system, we have significantly lowered the risk of adverse outcomes, including unintentional artificial ventilation.

\section{Delivery of Durable Medical Equipment}

The rapid, inevitable progression of the disease requires the efficient delivery of DME. This occurs at our ALS Center in two settings through the modification of current procedures. First, in typical circumstances on SCI and other divisions, the maximum disability is reached acutely (e.g., traumatic SCI or stroke), but in ALS many patients present with minimal disability. In this circumstance, the DME needs of the patient must be anticipated before they exist. In order to do this we have educated our existing occupational therapists and physical therapist to the natural progression of the disease. This allows us to provide such items as motorized wheelchairs, Hoyer lifts, and ramps and proceed with home modifications for patients that can still ambulate and carry out activities of daily living with minimal assistance. However, when disease progression occurs, DME is in place, preventing the need to accelerate processes to "catch up" to the patient's evolving disability level. The second setting occurs when unanticipated DME needs occur. In order to streamline the process of requesting DME, we have developed a Prosthetic template that alerts the purchasing officer that this request is for a Veteran with ALS. This prioritizes patients with ALS and allows for rapid payment and 
delivery of equipment. By doing this, patients' needs can be addressed in days rather than weeks, allowing us to correct acute issues, maintaining quality care in the home. One example of this would be a patient who had a PEG tube but was not tolerating bolus feeds because of abdominal discomfort. Instead of the patient going without nutrition for days or weeks while waiting for the delivery of a tube feeding pump system, the rapid prosthetics request sytem resulted in same-day delivery of the pump and resumption of delivery of nutrition within 24 hours.

\section{Regional Care and Telehealth}

The VA SCI system of care is designed to care for patients that have a high level of disability that makes routine travel to a specialty site difficult. The SCI system of care addresses this issue through a "hub and spokes" system of care. The system has centers of excellence (hubs) that provide specialty care to patients with SCI but also support regional VA primary care facilities (spokes) in caring for patients with SCI. This allows the SCI hub to provide consultative care over a large geographic area. This is the precise system of care proposed in the national directive for ALS care because, similar to patients with SCI, the high level of disability associated with ALS makes travel, even short distances, a complicated endeavor. At the Cleveland VA ALS Center, we have integrated into the pre-existing Cleveland SCI hub and spokes design, allowing us to care for patients up to 250 miles away. By doing so, we can extend high quality, specialty ALS consultation services to Veterans without the need to travel.

One of the most important tools for delivering care to regional spoke sites from the Cleveland SCI division is clinical video teleconferencing (telehealth). The Cleveland SCI division has a wellestablished telehealth program whereby patients go to their local VA, and with their primary care provider they have a face to face interaction with a specialty provider in Cleveland. This system has been utilized in Cleveland for patients with SCI with psychological, wound care, and rehabilitation needs that could not be met by the local spoke team alone. It is a primary mechanism by which specialty care reaches patients without the need to travel to Cleve- land. Logically, this system works equally as well for patients with ALS and effectively eliminates the need for most travel. In this way, travel is avoided as patients become more disabled but access to specialty care is not compromised. As the technology at the Cleveland VA evolves, we have been able to care for patients with advanced-stage ALS in their own home using a video interface. The video interface system allows for a face to face interaction over the patient's home computer using a secure Skype-like system of communication. We have used this system to continue to provide supportive and symptomatic care to patients with ALS confined to bed with hospice services. Finally, we have plans to use advanced video monitoring technology to transmit vital signs and other physiological measurements using integrated technology, further decreasing the need for patients with ALS to travel to our center but allowing us to more effectively care for them.

These examples demonstrate not only the malleability of the SCI service to accommodate ALS care but also the fact that an effective and extensive preexisting framework exists on the SCI division to deliver complex medical care to patients with high levels of disability. This makes the SCI division the most appropriate epicenter from which to develop an ALS interdisciplinary team within the VA system.

\section{Outcome Measures for ALS Patients in Cleveland and Beyond}

To facilitate the delivery of high-quality care, we have utilized several validated questionnaires and developed our own satisfaction assessment to determine the quality of care we are providing to Veterans with ALS. These include the McGill Quality of Life Questionnaire (MQOL), the ALS Functional Rating Scale-Revised (ALSFRS-R), and the Zarit Caregiver Burden Interview (ZBI). The initial cohort of patients $(n=15)$ evaluated by our center had a mean age of 66 years, was 87 percent Caucasian, and had a median time of 1 year from diagnosis to the first Cleveland VA ALS Center clinic appointment. Nearly all of these patients had received care elsewhere and nearly all of them had been evaluated by a neurologist (Table 1). 
Table 1.

Characteristics of patients with amyotrophic lateral sclerosis (ALS). Initial cohort of patients evaluated at Cleveland Department of Veterans Affairs ALS Center had been diagnosed on average more than 2 years before presenting. These resulted in unique set of needs and, in some cases, immediate end-of-life care planning.

\begin{tabular}{lc}
\hline \multicolumn{1}{c}{ Characteristic } & Result \\
\hline Age, yr (mean \pm SD) & $68 \pm 10.14$ \\
Race, $\%(n)$ & \\
$\quad$ White & $87(13)$ \\
$\quad$ African American & $13(2)$ \\
Previous ALS Provider, \% $(n)$ & $93(14)$ \\
$\quad$ Neurologist & $7(1)$ \\
$\quad$ Primary Care & \\
Years Diagnosed at 1st Clinic Visit (mean \pm SD) & $2.30 \pm 3.55$ \\
\hline SD = standard deviation. & \\
\hline \hline
\end{tabular}

\section{Quality of Life: $M Q O L$}

The MQOL is a widely used scale to assess subjective well-being in patients with life-threatening illnesses. The 16-item questionnaire focuses on the previous 2 days of the patient's life and also emphasizes existential qualities rather than just physical disability, a limitation of many quality of life measures. It has been validated in multiple settings [27$29]$ and has good intra- and interrater reliability $[27-28,30]$. The quality of life of our patients was comparable to historical ALS populations [31] with similar levels of disability measured using the ALSFRS-R (Table 2).

\section{Functional Status: ALSFRS-R}

The ALSFRS-R is a well-validated tool [32]. It has excellent intra- and interrater reliability (intraclass correlation coefficient $=0.93$, interclass correlation coefficient $=0.95$ ) [33] that is highly correlated with caregiver reports [34]. It assesses areas of daily function, specific symptoms, and degree of assistance required by a patient. These areas are graded on a 0 to 4 scale, with lower scores consistent with greater disability. Using this data on our initial cohort of 15 patients, we could understand the level of disability at which our patients were presenting for ALS care (Table 3).

\section{Caregiver Burden: ZBI}

The ZBI rates the physical, emotional, and financial effect of providing care to a patient. It has
Table 2.

Quality of life in patients with amyotrophic lateral sclerosis (ALS) McGill Quality of Life Questionnaire (MQOL) scores. Initial cohort's disability level and quality of life were comparable to published cohorts suggesting that care received before entering Department of Veterans Affairs (VA) system was adequate.

\begin{tabular}{lcc}
\hline \multicolumn{1}{c}{ Measure } & $\begin{array}{c}\text { Cleveland } \\
\text { VA ALS } \\
\text { Center }\end{array}$ & $\begin{array}{c}\text { Chiò et al., } \\
\text { 2004 [31] }\end{array}$ \\
\hline ALSFRS-R & 30 & 27 \\
Total MQOL & 6.59 & 6.30 \\
MQOL Domains & & \\
$\quad$ Physical Symptoms/Physical Well- & 5.15 & 6.15 \\
$\quad$ Being & & \\
$\quad$ Existential & 8.10 & 7.10 \\
Psychological & 4.61 & 5.70 \\
$\quad$ Support & 9.16 & 7.40 \\
\hline ALSFRS-R = ALS Functional Rating Scale-Revised. \\
\hline \hline
\end{tabular}

Table 3.

Functional status of patients with amyotrophic lateral sclerosis (ALS). Initial cohort's level of disability was determined using ALS Functional Rating Scale-Revised (ALSFRS-R). This scale divides symptoms into 12 distinct categories, and then patients rate disability on 0 to 4 scale.

\begin{tabular}{lc}
\hline \multicolumn{1}{c}{ ALSFRS-R Domains } & Mean \pm SD \\
\hline Speech & $3.11 \pm 1.23$ \\
Salivation & $2.72 \pm 1.45$ \\
Swallowing & $2.72 \pm 1.41$ \\
Handwriting & $2.67 \pm 1.13$ \\
Cutting Food & $2.50 \pm 1.10$ \\
Dressing and Hygiene & $2.06 \pm 1.26$ \\
Turning in Bed and Adjusting Bedclothes & $2.61 \pm 1.20$ \\
Walking & $2.39 \pm 1.20$ \\
Climbing Stairs & $1.17 \pm 1.30$ \\
Dyspnea & $2.83 \pm 1.25$ \\
Orthopnea & $2.89 \pm 1.08$ \\
Respiratory Insufficiency & $3.18 \pm 1.25$ \\
\hline SD $=$ standard deviation. & \\
\hline \hline
\end{tabular}

been estimated that on average a caregiver to a patient with ALS spends more than $11 \mathrm{~h} / \mathrm{d}$ providing care, even with assistance in the home [35]. Furthermore, the caregiver may significantly affect a patient with ALS's mental and physical well-being [31]. The ZBI is a 22-point questionnaire using a 5point Likert scale $(0=$ never, $5=$ always $)$, with higher scores reflecting higher caregiver burden. It was developed and validated in dementia caregivers but has been used in multiple populations and is useful for assessing the burden to caregivers of 
neurodegenerative conditions overall [36]. The caregivers of our patients $(n=18)$ had a surprisingly low ZBI score despite a relatively high level of disability (Table 4).

\section{Educational Needs and Satisfaction with Care}

Finally, our own satisfaction assessment (Appendixes 1 and 2, available online only) is divided into eight major components of ALS care and includes components of education critical to decision-making processes in patients with ALS. These include overall ALS management, speech therapy, respiratory education, PEG placement education, occupational therapy, home evaluation, education regarding prognosis, and education regarding end of life. We believe that early education regarding end-of-life decisions and palliative options is critical for a patient to make informed decisions and remain in control of his or her healthcare. Because most of our patients initially were referred from other private sector ALS centers, we were able to compare our ability to educate and manage patients with these centers by utilizing the questionnaire on their initial visit and then at their 3 month follow-up appointment with our center. The percentage of patients receiving components of care or education from other ALS centers was lower than we had anticipated (Figure (a)). Furthermore, in areas of education regarding palliative and end-of-life care, patients rated their experiences at outside centers lower than we anticipated (Figure (b)). These data have been important in helping us refine our clinical practices and in the modification of our educational materials.

\section{Table 4.}

Level of caregiver burden. Zarit Caregiver Burden Interview (ZBI) is 22-point questionnaire using 5-point Likert scale $(0=$ never, $5=$ always) with higher scores reflecting higher caregiver burden. Changes in score can alert amyotrophic lateral sclerosis center to particular in-home needs that can then be addressed.

\begin{tabular}{lc}
\hline ZBI Category Level of Burden & Percent of Caregivers \\
\hline None-Mild & 83 \\
Mild-Moderate & 17 \\
Moderate-Severe & 0 \\
Severe & 0 \\
\hline \hline
\end{tabular}
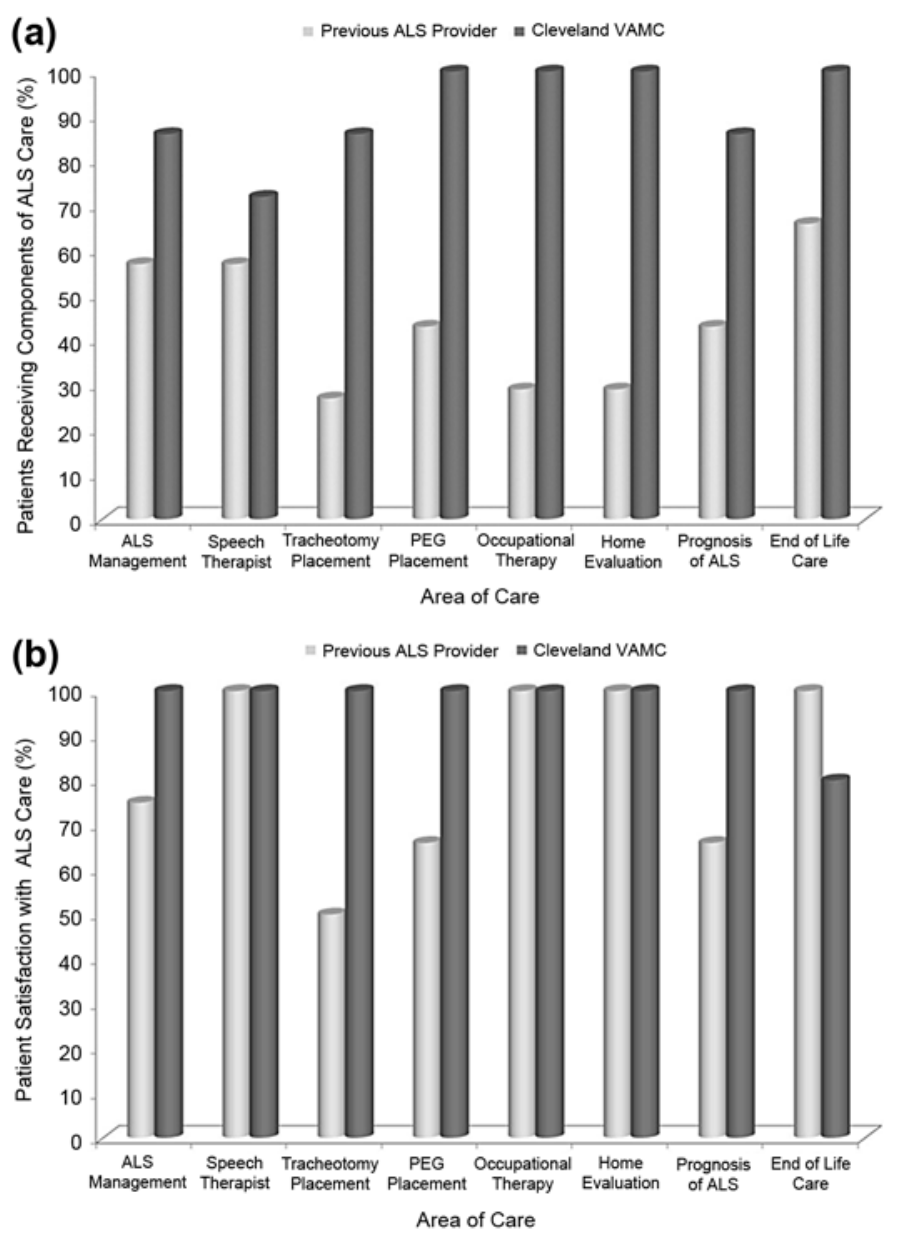

Figure.

Care received and satisfaction with care. (a) Percentage of patients receiving components of care or education from previous amyotrophic lateral sclerosis (ALS) centers was lower than we had anticipated. (b) Furthermore, in areas of education regarding palliative and end of life care, patients rated their experiences at outside centers lower than we anticipated. PEG = percutaneous endoscopic gastrostomy, VAMC = Department of Veterans Affairs Medical Center.

\section{CONCLUSIONS}

The decision to make ALS a compensable illness has resulted in an influx of patients into the VA system. These patients have complex needs and progressive disability requiring a high level of coordinated care. We have developed an ALS system of care within a VA SCI Center by modifying the preexisting framework and integrating other services into our care team. Within this system, we have been able to effectively address the needs of 
patients with ALS, achieving levels of satisfaction equal to or exceeding that of private centers. Our success suggests that the SCI division should act as the coordinating service for providing care and services to patients with ALS within the VA system.

\section{ACKNOWLEDGMENTS}

The views expressed in this article are those of the authors and do not necessarily represent the position or policy of VA or the Department of Defense.

Frances McClellan, RN, MSN; ${ }^{1}$ Monique Washington, $R N, M S ;^{1}$ Robert Ruff, MD, PhD $;^{2-3}$ Stephen M. Selkirk, MD, PhD ${ }^{1,3 *}$

${ }^{1}$ Spinal Cord Injury Division, and ${ }^{2}$ Department of Neurology, Louis Stokes Cleveland VA Medical Center, Cleveland, OH; ${ }^{3}$ Case Western Reserve Medical School, Department of Neurology, Cleveland, $\mathrm{OH}$

*Email: stephen.selkirk@,va.gov

\section{REFERENCES}

1. Czaplinski A, Yen AA, Simpson EP, Appel SH. Slower disease progression and prolonged survival in contemporary patients with amyotrophic lateral sclerosis: is the natural history of amyotrophic lateral sclerosis changing? Arch Neurol. 2006;63(8):1139-43. [PMID:16908741] http://dx.doi.org/10.1001/archneur.63.8.1139

2. Bensimon G, Lacomblez L, Meininger V; ALS/Riluzole Study Group. A controlled trial of riluzole in amyotrophic lateral sclerosis. N Engl J Med. 1994; 330(9):585-91. [PMID:8302340] http://dx.doi.org/10.1056/NEJM199403033300901

3. Miller RG, Mitchell JD, Moore DH. Riluzole for amyotrophic lateral sclerosis (ALS)/motor neuron disease (MND). Cochrane Database Syst Rev. 2012;3: CD001447. [PMID:22419278]

4. Weisskopf MG, O'Reilly EJ, McCullough ML, Calle EE, Thun MJ, Cudkowicz M, Ascherio A. Prospective study of military service and mortality from ALS.
Neurology. 2005;64(1):32-37. [PMID:15642900] http://dx.doi.org/10.1212/01.WNL.0000148649.17706.D9

5. Logroscino G, Traynor BJ, Hardiman O, Chiò A, Mitchell D, Swingler RJ, Millul A, Benn E, Beghi E; EURALS. Incidence of amyotrophic lateral sclerosis in Europe. J Neurol Neurosurg Psychiatry. 2010; 81(4):385-90. [PMID:19710046] http://dx.doi.org/10.1136/jnnp.2009.183525

6. McGuire V, Longstreth WT Jr, Koepsell TD, van Belle G. Incidence of amyotrophic lateral sclerosis in three counties in western Washington state. Neurology. 1996;47(2):571-73. [PMID:8757041] http://dx.doi.org/10.1212/WNL.47.2.571

7. Kamel F, Umbach DM, Bedlack RS, Richards M, Watson M, Alavanja MC, Blair A, Hoppin JA, Schmidt S, Sandler DP. Pesticide exposure and amyotrophic lateral sclerosis. Neurotoxicology. 2012;33(3):457-62. [PMID:22521219] http://dx.doi.org/10.1016/j.neuro.2012.04.001

8. Armon C, Nelson LM. Is head trauma a risk factor for amyotrophic lateral sclerosis? An evidence based review. Amyotroph Lateral Scler. 2012;13(4):351-56. [PMID:22424129] http://dx.doi.org/10.3109/17482968.2012.660954

9. Longstreth WT, McGuire V, Koepsell TD, Wang Y, van Belle G. Risk of amyotrophic lateral sclerosis and history of physical activity: a population-based case-control study. Arch Neurol. 1998;55(2):201-6. [PMID:9482362] http://dx.doi.org/10.1001/archneur.55.2.201

10. Callaghan B, Feldman D, Gruis K, Feldman E. The association of exposure to lead, mercury, and selenium and the development of amyotrophic lateral sclerosis and the epigenetic implications. Neurodegener Dis. 2011;8(1-2):1-8. [PMID:20689252] http://dx.doi.org/10.1159/000315405

11. Smith TC, Gray GC, Knoke JD. Is systemic lupus erythematosus, amyotrophic lateral sclerosis, or fibromyalgia associated with Persian Gulf War service? An examination of Department of Defense hospitalization data. Am J Epidemiol. 2000;151(11): 1053-59. [PMID:10873128] http://dx.doi.org/10.1093/oxfordjournals.aje.a010147

12. Haley RW. Excess incidence of ALS in young Gulf War veterans. Neurology. 2003;61(6):750-56. [PMID:14504316] http://dx.doi.org/10.1212/WNL.61.6.750

13. Horner RD, Kamins KG, Feussner JR, Grambow SC, Hoff-Lindquist J, Harati Y, Mitsumoto H, Pascuzzi R, 
Spencer PS, Tim R, Howard D, Smith TC, Ryan MA, Coffman CJ, Kasarskis EJ. Occurrence of amyotrophic lateral sclerosis among Gulf War veterans. Neurology. 2003;61(6):742-49. [PMID:14504315] http://dx.doi.org/10.1212/01.WNL.0000069922.32557.CA

14. Coffman CJ, Horner RD, Grambow SC, Lindquist J; VA Cooperative Studies Program Project \#500. Estimating the occurrence of amyotrophic lateral sclerosis among Gulf War (1990-1991) veterans using capturerecapture methods. Neuroepidemiology. 2005;24(3): 141-50. [PMID:15650320] http://dx.doi.org/10.1159/000083297

15. Armon C. Occurrence of amyotrophic lateral sclerosis among Gulf War veterans. Neurology. 2004; 62(6):1027, author reply 1027-29. [PMID:15037726] http://dx.doi.org/10.1212/WNL.62.6.1027

16. Institute of Medicine. Amyotrophic lateral sclerosis in veterans: review of the scientific literature. Washington (DC): National Academy Press; 2006.

17. Ruff R. Amyotropic lateral sclerosis system of care procedures. Washington (DC): VHA; 2013.

18. Gordon PH, Salachas F, Lacomblez L, Le Forestier N, Pradat PF, Bruneteau G, Elbaz A, Meininger V. Predicting survival of patients with amyotrophic lateral sclerosis at presentation: A 15-year experience. Neurodegener Dis. 2012. Epub ahead of print.

19. Fujimura-Kiyono C, Kimura F, Ishida S, Nakajima H, Hosokawa T, Sugino M, Hanafusa T. Onset and spreading patterns of lower motor neuron involvements predict survival in sporadic amyotrophic lateral sclerosis. J Neurol Neurosurg Psychiatry. 2011; 82(11):1244-49. [PMID:21921087] http://dx.doi.org/10.1136/jnnp-2011-300141

20. Traynor BJ, Alexander M, Corr B, Frost E, Hardiman O. Effects of multidisciplinary amyotrophic lateral sclerosis (ALS) clinic on ALS survival: a population based study, 1996-2000. J Neurol Neurosurg Psychiatry. 2003;74(9):1258-61. [PMID:12933930] http://dx.doi.org/10.1136/jnnp.74.9.1258

21. Van den Berg JP, Kalmijn S, Lindeman E, Veldink $\mathrm{JH}$, de Visser M, Van der Graaff MM, Wokke JH, Van den Berg LH. Multidisciplinary ALS care improves quality of life in patients with ALS. Neurology. 2005;65(8):1264-67. [PMID:16247055] http://dx.doi.org/10.1212/01.wnl.0000180717.29273.12

22. Chiò A, Bottacchi E, Buffa C, Mutani R, Mora G; PARALS. Positive effects of tertiary centres for amyotrophic lateral sclerosis on outcome and use of hospital facilities. J Neurol Neurosurg Psychiatry.
2006;77(8):948-50. [PMID:16614011]

http://dx.doi.org/10.1136/jnnp.2005.083402

23. Bourke SC, Tomlinson M, Williams TL, Bullock RE, Shaw PJ, Gibson GJ. Effects of non-invasive ventilation on survival and quality of life in patients with amyotrophic lateral sclerosis: a randomised controlled trial. Lancet Neurol. 2006;5(2):140-47.

[PMID:16426990]

http://dx.doi.org/10.1016/S1474-4422(05)70326-4

24. Miller RG, Jackson CE, Kasarskis EJ, England JD, Forshew D, Johnston W, Kalra S, Katz JS, Mitsumoto H, Rosenfeld J, Shoesmith C, Strong MJ, Woolley SC; Quality Standards Subcommittee of the American Academy of Neurology. Practice parameter update: the care of the patient with amyotrophic lateral sclerosis: drug, nutritional, and respiratory therapies (an evidence-based review): report of the Quality Standards Subcommittee of the American Academy of Neurology. Neurology. 2009;73(15): 1218-26. [PMID:19822872] http://dx.doi.org/10.1212/WNL.0b013e3181bc0141

25. Lechtzin N, Scott Y, Busse AM, Clawson LL, Kimball R, Wiener CM. Early use of non-invasive ventilation prolongs survival in subjects with ALS. Amyotroph Lateral Scler. 2007;8(3):185-88. [PMID:17538782] http://dx.doi.org/10.1080/17482960701262392

26. Czaplinski A, Yen AA, Appel SH. Forced vital capacity (FVC) as an indicator of survival and disease progression in an ALS clinic population. J Neurol Neurosurg Psychiatry. 2006;77(3):390-92. [PMID:16484652] http://dx.doi.org/10.1136/jnnp.2005.072660

27. Cohen SR, Mount BM, Strobel MG, Bui F. The McGill Quality of Life Questionnaire: a measure of quality of life appropriate for people with advanced disease. A preliminary study of validity and acceptability. Palliat Med. 1995;9(3):207-19.

[PMID:7582177]

http://dx.doi.org/10.1177/026921639500900306

28. Cohen SR, Mount BM, Bruera E, Provost M, Rowe J, Tong K. Validity of the McGill Quality of Life Questionnaire in the palliative care setting: a multicentre Canadian study demonstrating the importance of the existential domain. Palliat Med. 1997;11(1): 3-20. [PMID:9068681]

http://dx.doi.org/10.1177/026921639701100102

29. Cohen SR, Hassan SA, Lapointe BJ, Mount BM. Quality of life in HIV disease as measured by the 
McGill quality of life questionnaire. AIDS. 1996; 10(12):1421-27. [PMID:8902073] http://dx.doi.org/10.1097/00002030-199610000-00016

30. Cohen SR, Mount BM. Living with cancer: "good" days and "bad" days - what produces them? Can the McGill quality of life questionnaire distinguish between them? Cancer. 2000;89(8):1854-65. [PMID:11042583] http://dx.doi.org/10.1002/10970142(20001015)89: 8<1854::AID-CNCR28>3.3.CO;2-3

31. Chiò A, Gauthier A, Montuschi A, Calvo A, Di Vito N, Ghiglione P, Mutani R. A cross sectional study on determinants of quality of life in ALS. J Neurol Neurosurg Psychiatry. 2004;75(11):1597-1601. [PMID:15489393] http://dx.doi.org/10.1136/jnnp.2003.033100

32. Cedarbaum JM, Stambler N. Performance of the Amyotrophic Lateral Sclerosis Functional Rating Scale (ALSFRS) in multicenter clinical trials. J Neurol Sci. 1997;152(Suppl 1):S1-9. [PMID:9419047] http://dx.doi.org/10.1016/S0022-510X(97)00237-2

33. Kaufmann P, Levy G, Montes J, Buchsbaum R, Barsdorf AI, Battista V, Arbing R, Gordon PH, Mitsumoto H, Levin B, Thompson JL; QALS study group. Excellent inter-rater, intra-rater, and telephoneadministered reliability of the ALSFRS-R in a multicenter clinical trial. Amyotroph Lateral Scler. 2007; 8(1):42-46. [PMID:17364435] http://dx.doi.org/10.1080/17482960600888156

34. Kasarskis EJ, Dempsey-Hall L, Thompson MM, Luu LC, Mendiondo M, Kryscio R. Rating the severity of
ALS by caregivers over the telephone using the ALSFRS-R. Amyotroph Lateral Scler Other Motor Neuron Disord. 2005;6(1):50-54. [PMID:16036426] http://dx.doi.org/10.1080/14660820510027107

35. Krivickas LS, Shockley L, Mitsumoto H. Home care of patients with amyotrophic lateral sclerosis (ALS). J Neurol Sci. 1997;152(Suppl 1):S82-89. [PMID:9419061] http://dx.doi.org/10.1016/S0022-510X(97)00251-7

36. Jenkinson C, Peters M, Bromberg MB. Quality of life measurement in neurodegenerative and related conditions. Cambridge (England): Cambridge University Press; 2011.

This article and any supplementary material should be cited as follows:

McClellan F, Washington M, Ruff R, Selkirk SM. Developing a system of care for ALS patients at the Louis Stokes Cleveland VA Medical Center, Spinal Cord Injury Division. J Rehabil Res Dev. 2013; 50(2):vii-xviii.

http://dx.doi.org/10.1682/JRRD.2012.12.0237

ResearcherID: Stephen M. Selkirk, MD, PhD: F-36552011

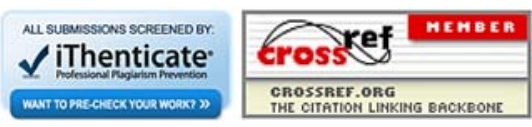

